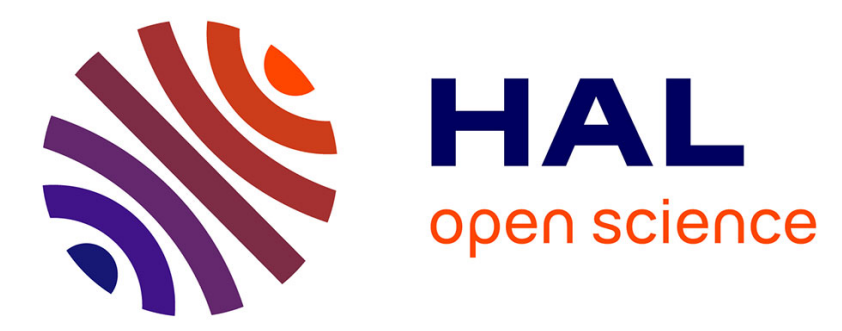

\title{
On the Efficiency of TRIZ Application for Process Intensification in Process Engineering
}

Pavel Livotov, Mas Udah, Arun Prasad Chandra Sekaran

\section{To cite this version:}

Pavel Livotov, Mas Udah, Arun Prasad Chandra Sekaran. On the Efficiency of TRIZ Application for Process Intensification in Process Engineering. 18th TRIZ Future Conference (TFC), Oct 2018, Strasbourg, France. pp.126-140, 10.1007/978-3-030-02456-7_11 . hal-02279972

\section{HAL Id: hal-02279972 \\ https://hal.inria.fr/hal-02279972}

Submitted on 5 Sep 2019

HAL is a multi-disciplinary open access archive for the deposit and dissemination of scientific research documents, whether they are published or not. The documents may come from teaching and research institutions in France or abroad, or from public or private research centers.
L'archive ouverte pluridisciplinaire HAL, est destinée au dépôt et à la diffusion de documents scientifiques de niveau recherche, publiés ou non, émanant des établissements d'enseignement et de recherche français ou étrangers, des laboratoires publics ou privés.

\section{(c)(1)}

Distributed under a Creative Commons Attribution| 4.0 International License 


\title{
On the Efficiency of TRIZ Application for Process Intensification in Process Engineering
}

\author{
Pavel Livotov, Mas'udah, Arun Prasad Chandra Sekaran \\ Offenburg University of Applied Sciences, Badstr. 24, 77652 Offenburg, Germany
}

\begin{abstract}
In recent years, the application of TRIZ methodology in the process engineering has been found promising to develop comprehensive inventive solution concepts for process intensification (PI). However, the effectiveness of TRIZ for PI is not measured or estimated. The paper describes an approach to evaluate the efficiency of TRIZ application in process intensification by comparing six case studies in the field of chemical, pharmaceutical, ceramic, and mineral industries. In each case study, TRIZ workshops with the teams of researchers and engineers has been performed to analyze initial complex problem situation, to identify problems, to generate new ideas, and to create solution concepts. The analysis of the workshop outcomes estimates fulfilment of the PI-goals, impact of secondary problems, variety and efficiency of ideas and solution concepts. In addition to the observed positive effect of TRIZ application, the most effective inventive principles for process engineering have been identified.
\end{abstract}

Keywords: TRIZ Efficiency, Process Engineering, Process Intensification.

\section{$1 \quad$ Introduction}

Innovation in process engineering is becoming more challenging in developing new processes or in transforming conventional chemical processes into more economical, productive, and environmental friendly. Process Intensification (PI) is a knowledgebased innovation methodology evolved over the last three decades mainly for gas-liquid systems, is focusing now on processes involving solids handling [1]. Besides its basic concept of equipment miniaturization, the new PI equipment and methods enable to substitute common batch processes into faster and safer continuous processes with higher efficiency, productivity, and reduced costs [1].

PI is expected not only to improve processes and resulting products, but also able to bring a high value profit through innovation. However, due to the secondary problems, the implementation of the novel PI apparatus and methods is not as simple as perceived. The use of systematic creativity approaches for PI seems to be an opportunity to faster overcome the secondary problems. Therefore, in the last few years the analytical and inventive tools of the theory of inventive problem solving TRIZ [2] have been applied for intensification of various processes to ensure PI goals are achieved. As outlined in [3], TRIZ helps to identify secondary problems of PI and limits these negative side 
effects. The benefits of TRIZ approach above conventional creativity methods in practice are reported in several interdisciplinary domains $[4,5,6]$, as well as in the field of process engineering $[7,8]$ and in particular of chemical processes [10]. The authors of [8] adapt TRIZ contradiction matrix to resolve contradictions related to process engineering problems. Their research proposes new characteristics and inventive principles for TRIZ contradiction matrix to counter problems in chemical process industries. Another work introduces TRIZ methodology and framework for problem solving and forecasting of product development in chemical engineering [11]. Furthermore, the authors of [12] demonstrate that TRIZ-based approach is well-suited for accelerating innovation in chemical engineering. Additionally, TRIZ application has been modified and enhanced to the design of inherently safer chemical processes [13]. The coupling of TRIZ with the Case-Based Reasoning in chemical engineering is proposed in [14], and the advantages of linking TRIZ and Process Intensification are disclosed in [17]. Evidently, TRIZ helps engineers to create inventive solutions and to deliver radical improvements, but it still shows lower application level in industrial practice, ranking for example with $14 \%$ in fifth place of the top five creativity methods supporting innovation process in German companies [15]. Therefore, the objective evaluation of the TRIZ effectiveness for process engineering remains a significant research issue.

This paper presents an effort to evaluate the efficiency of TRIZ application in process intensification involving solids handling through six case studies assessment in the field of chemical, pharmaceutical, ceramic, and mineral industries as shown in Table 1.

Table 1. Six case studies of intensification of processes involving solid handling.

\begin{tabular}{cl}
\hline Case study (CS) & Process description \\
\hline CS1 & Separation of ceramic-metal powders \\
CS2 & Dry granulation of ceramic powders \\
CS3 & Metal ore beneficiation \\
CS4 & Granulation of pharmaceutical powders \\
CS5 & Drying of pharmaceutical powders \\
CS6 & Mixing of chemical reagents \\
\hline
\end{tabular}

To reach the research objectives, in each case study a one or two-days TRIZ workshop was prepared, carried-out and evaluated with the team of researchers and engineers. Each TRIZ workshop emphases on improving abilities in systematic problem definition and ideation. It starts with the comprehensive analysis of the initial problem situation and ends with the creation of alternative or complimentary solution concepts for the PI case studies. The objective measures of ideation effectiveness defined in [16] such as variety, quantity and quality of proposed novel ideas and solution concepts are documented and evaluated. The corresponding most effective TRIZ inventive principles and sub-principles frequently used in creation of PI solution concepts are identified. Additionally, a few months later review is conducted for each case study to observe and evaluate the positive effect of TRIZ application in the practice. 


\section{Case Study Overview}

\subsection{CS1 - Separation of Ceramic-Metal Powders}

The case study CS1 aims to intensify the powder classification system for separation of ceramic-metal powders produced by high energy ball milling. The system should be able to divide the input powder by mass or size without disposable parts, in continuous and without human intervention for powder handling. Even though the existing system of air classification and sieving system is simple and flexible for powders classification, it still has disadvantages on discontinuous process, generation of fine phase in milling process and generation of environmental contaminant particles.

\subsection{CS2 - Dry granulation of Ceramic Powders}

High shear mixer granulator (HSMG) is an established technology for dry route of ceramic powders granulation with lower energy and water consumption which is not shown in wet route processing. However, dry granulation contains many constraints regarding final granulated product such as higher moisture content, bimodal size distribution and low productivity. Therefore, the main challenge of case study is to produce granulated powders with adequate physical and chemical properties through the dry route with the same properties as the ones obtained through the wet route.

\subsection{CS3 - Metal Ore Beneficiation}

In mineral beneficiation processes, on-line mineral analysis based on Raman spectroscopy monitors mineral concentrations at selected locations along the process line. Routine operation of the system is easy and can be carried out by persons who have no indepth knowledge about the fundamentals of Raman spectroscopy. Nevertheless, undesired measurement deviations caused by the presence of dark and different minerals, varying particle size of incoming ore, varying solids content and poor representability of the sampling have to be minimized.

\subsection{CS4 - Wet Granulation of Pharmaceutical Powders}

The objective for this case study is to perform wet granulation of pharmaceutical powders in a single shift which is currently carried out in four shifts. This method would reduce the number of granulations per batch, and in consequence, decrease the process time per batch. The main task of the new process is to obtain stable homogeneous granules in a wet high-speed mixer, with set dissolution and other analytical specifications achievable in the current process.

\subsection{CS5 - Drying of Pharmaceutical Powders}

Drying is one of the heart processes in granulation of pharmaceutical powders. Spiral Flash Dryer (SFD) is a swirling fluidized bed reactor [1] and can be considered as an alternative to conventional flash dryers and other fluid bed applications. The SFD is designed to dry granules with a minimal amount of drying air and providing intrinsic 
separation of dry particles from wet particles, which are recirculated and dried further. In addition, the operating principle is similar with an expanded fluid bed, with a very short residence time, maintaining a fast-drying effect due to the high-induced turbulence. The intensification goal of this case study is preventing undesired properties of SFD such as moisture deviation, generation of fine dry powders and sticky product over the equipment (fouling of solids).

\subsection{CS6 - Mixing of Chemical Reagents}

The CoFlore ${ }^{\circledR}$ Agitated Tube Reactor is a general purpose dynamically agitated chemical reactor, and therefore offers a range of applications as broad as that of existing batch reactor technology [1]. It can handle a large variety of reaction schemes, sequences, processes, and phase combinations over a wide range of reaction and residence times. Additionally, it also gives high level of mixing, reduces the required maintenance, and improves operational life of the reactor, allowing for easy disassembly and cleaning. However, the system should be enhanced to give the best possible mixing characteristics, to increase uniformity of solid distribution, to enable scalability of reactor, and to avoid fouling of solids.

\section{Research Approach}

Concerning inventive problem solving for process intensification, TRIZ offers a systematic direction to figure out ideas and solutions for developing new technology or improving the existing one. Even though TRIZ does not give directly an applicable solution, it helps to generate novel ideas faster and provides a basis for selecting the best ideas [14]. According to the Advanced Innovation Design Approach (AIDA) for process engineering [7], the application of TRIZ follows a process with a series of phases:

I. Identification, analysis and ranking of partial problems.

II. Systematic idea generation with TRIZ inventive principles.

III. Creation of the solution concepts.

IV. Concepts optimization with elimination of the negative side effects.

In this research work, the first 3 process phases (I, II and III) were performed during TRIZ workshops in each of six case studies, with the process engineers and academia researchers, currently involved in the corresponding PI projects. Each workshop was carried out under the guidance of one TRIZ specialist as moderator within 1 or 2 days with $6 \ldots 9$ participants working in smaller teams of $2 \ldots 3$ persons. The relative duration of the single workshop phases was I - $25 \%$, II - $50 \%$, III - $25 \%$ of the total time. The ideation phase II comprised one ideation session in the one-day workshops (CS1, CS3), and two ideation sessions in the two days workshops (CS2, CS4, CS5, CS6). The presented research assesses the efficiency of TRIZ application for problem solving, idea generation and concepts creation. Due to the time limit attached to the workshop duration, the process phase IV "Concepts optimization" was not a part of the workshops. 


\subsection{Phase I: Problems Identification, Analysis and Ranking}

The approach starts with analyzing initial situation of process intensification using innovation situation questionnaire, followed by the comprehensive problem analysis including understanding primary function of equipment, operation, environment and working conditions for each case study. Function analysis and process mapping techniques [7] break down the complete production process into unit operations which results in identification of useful functions and undesired properties of unit operations. Finally, identification of the key negative effects or disadvantage of the analyzed system in accordance to the principles of Cause Effect Chain Analysis and Root-Conflict Analysis RCA+ [2], helps workshop participants to identify the root causes of problems and to rank them accordingly the objectives of process intensification in each case study, as presented in Table 2. The problems were formulated in detail as (a) enhancement of insufficient positive function, (b) elimination of negative effect or (c) engineering or physical contradiction.

Table 2. List of partial problems with higher ranking in case studies.

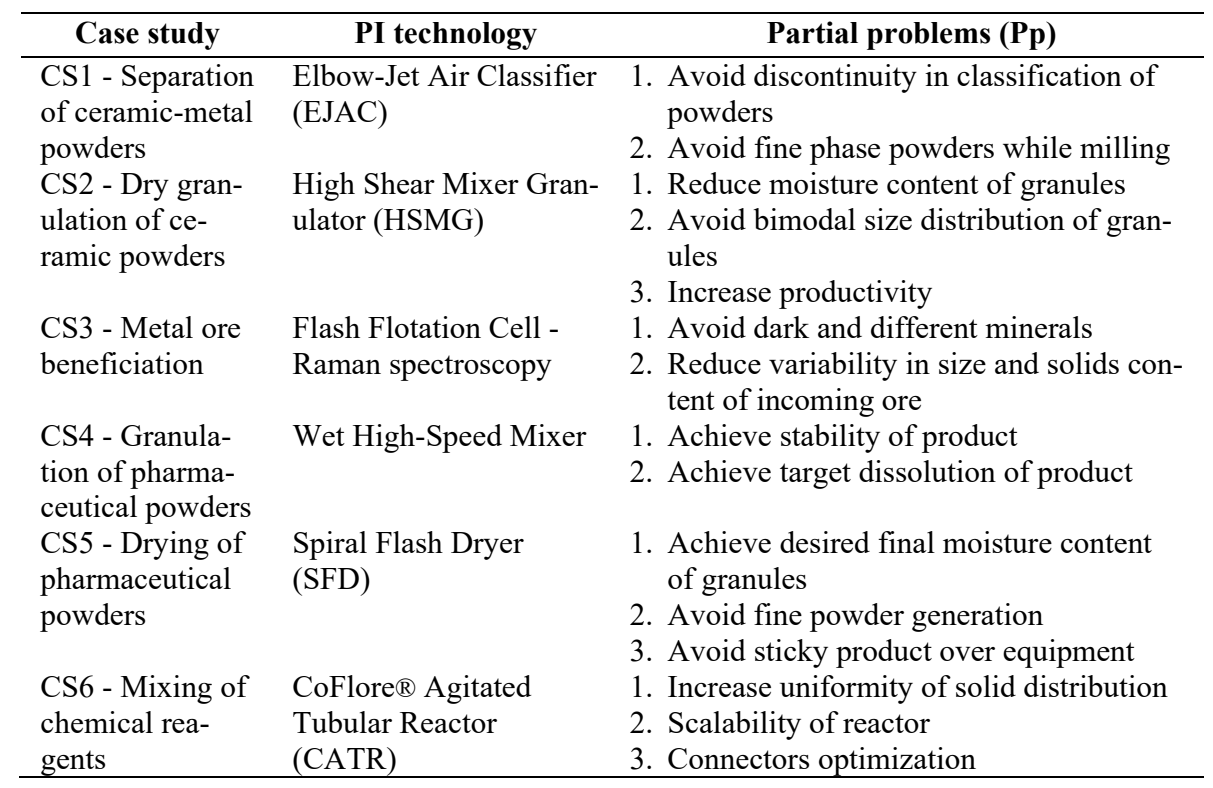

\subsection{Phase II: Systematic Idea Generation with TRIZ}

As a majority of workshop participants were not skilled in the TRIZ methodology, this phase of the workshop required a 45 minutes introduction to the TRIZ basics with a short training in application of 40 inventive principles. The enhanced version of 40 inventive principles with in total 160 sub-principles [17] was applied in the workshops as a universal ideation tool convenient both for process engineers and researchers. The 
idea generation was also supported by solutions examples in chemical and process engineering known in TRIZ literature $[18,19]$. The application of the principles was performed for each partial problem separately in the order proposed in Table 3, whereby each idea generation phase was started with statistically strongest principles (group 1), optionally followed by the group 2 in case of design problems or group 3 for process optimization problems. All generated ideas were documented with a description and mandatory drawing and assigned to the inventive principles they were based on.

As a rule, different partial problems presented in the Table 2, were operated by different working teams. If more than one team worked on same partial problem, each team applied different TRIZ inventive principles to avoid similar ideas.

Table 3. Recommended order for application of 40 inventive principles.

\begin{tabular}{ll}
\hline $\begin{array}{l}\text { Group 1: } \\
\text { Statistically strongest } \\
\text { principles [9] }\end{array}$ & $\begin{array}{l}\text { (35) Transform physical and chemical properties, (10) Prior useful } \\
\text { action, (1) Segmentation, (28) Replace mechanical working princi- } \\
\text { ple, (2) Leaving out / Trimming, (15) Dynamism and adaptability, } \\
\text { (19) Periodic action, (3) Local quality, (17) Shift to another dimen- } \\
\text { sion, (13) Inversion, (18) Mechanical vibration, (26) Copying. }\end{array}$ \\
$\begin{array}{l}\text { Group 2: } \\
\text { Principles for solving } \\
\text { design problems }\end{array}$ & $\begin{array}{l}\text { (6) Universality, (5) Combining, (29) Pneumatic or hydraulic con- } \\
\text { structions, (30) Flexible shells or thin films, (7) Nesting / Integra- } \\
\text { tion, (8) Anti-weight, (4) Asymmetry, (40) Composite materials, } \\
\text { (24) Mediator, (14) Spheroidality and Rotation, (23) Feedback and }\end{array}$ \\
$\begin{array}{l}\text { automation, (31) Porous materials, (25) Self-service. } \\
\text { Group 3: }\end{array}$ & $\begin{array}{l}\text { (16) Partial or excessive action, (27) Disposability / Cheap short } \\
\text { problems in Process } \\
\text { Engineering }\end{array}$ \\
$\begin{array}{l}\text { (21) Skipping / Rushing through, (11) Preventive measure / Cush- } \\
\text { ion in advance, (33) Homogeneity, (22) Converting harm into ben- } \\
\text { efit, (39) Inert environment, (37) Thermal expansion, (36) Phase } \\
\text { transitions, (38) Strong oxidants, (34) Rejecting and regenerating } \\
\text { parts, (12) Equipotentiality, (9) Prior counteraction of harm. }\end{array}$ \\
\hline
\end{tabular}

The Fig. 1 shows statistics of inventive principles of three groups applied by the participants during TRIZ workshops for idea generation. The lowest amount of the inventive principles was used in one-day workshops with one ideation session (CS1 - 8 principles; CS3 - 11 principles).

\begin{tabular}{|c|c|c|c|c|c|c|}
\hline & & 12 & 10 & 10 & $10^{11}$ & \\
\hline & Case study 1 & Case study 2 & Case study 3 & Case study 4 & Case study 5 & Case study 6 \\
\hline -Group 1 & 7 & 12 & 10 & 10 & 10 & 10 \\
\hline QGroup 2 & 1 & 4 & 1 & 3 & 11 & 5 \\
\hline QGroup 3 & 0 & 3 & 0 & 1 & 2 & 1 \\
\hline
\end{tabular}

Fig. 1. Amount of inventive principles in corresponding groups applied in the case studies. 
The number of principles used in two-days workshops with accordingly two ideation session (CS2, CS4, CS5, CS6) varies between 14 and 23. The ideation session duration was on average 3 hours including idea generation (1,5 hours) and idea presentation and discussion (1,5 hours). The identification of the most effective inventive principles and corresponding sub-principles applied by the participants for idea generation was one of the tasks in presented research.

\subsection{Phase III: Concepts Creation}

Idea generation phase provides solution ideas for the partial problems with different stages of concretization. To develop a new solution concept at least one solution idea must be selected for each partial problem. Thus, a robust solution concept delivers solutions for all partial problems. Workshop participants with their specific knowledge on processes, existing and new technologies are in position to select most promising ideas overcoming the partial problems and to combine complementary partial solutions into solution concepts. Due to the multi-objective aspect of the concept creation and optimization, more than one solution concept can be designed in this phase, including "best performance", "minimum cost" or "optimal performance to cost ratio" conceptual alternatives. Therefore, the creation of solution concepts in a situation comprising several problems remains one of the challenging phases in the workshops. For example, Table 4 compares briefly six solution concepts developed in case study 5 (CS5) from in total 52 ideas. As one can see, the concepts C1 - C5 contain solutions for all three partial problems, and the concept $\mathrm{C} 6$ offers solutions for the problems 1 and 3 only.

Table 4. Amount of ideas selected for use in 6 solution concepts of the case study CS5.

\begin{tabular}{cccccccc}
\hline Partial prob- & $\begin{array}{c}\text { Solution } \\
\text { lems (Pp) }\end{array}$ & \multicolumn{6}{c}{ Ideas selected for solution concepts C1 - C6 } \\
\cline { 2 - 8 } & ideas & $\mathbf{C 1}$ & $\mathbf{C 2}$ & $\mathbf{C 3}$ & $\mathbf{C 4}$ & $\mathbf{C 5}$ & $\mathbf{C 6}$ \\
\hline Pp1 & 31 & 3 & 3 & 1 & 1 & 2 & 4 \\
Pp2 & 9 & 2 & 1 & 1 & 1 & 1 & - \\
Pp3 & 12 & 2 & 1 & 3 & 1 & 3 & 1 \\
\hline Total & 52 ideas & 7 ideas & 5 ideas & 5 ideas & 3 ideas & 6 ideas & 5 ideas \\
\hline
\end{tabular}

\section{Discussion of Results}

\subsection{TRIZ Impact on Quantity and Novelty of proposed Ideas}

The quantitative analysis of the case studies undoubtedly shows that TRIZ methodology can effectively support the process intensification tasks in the industry and with 234 novel ideas and 28 solution concepts for 15 partial problems consistently yields good results in the variety and novelty of ideas and solution concepts. It is important to note that in each case study all problem-solving attempts and ideas known prior to the workshops were documented in the initial situation questionnaire. Thus, the discussed ideation outcome of the workshops includes different ideas only, new to the initial situation. In other words, all 234 solution ideas can be considered as dissimilar and novel. 
Furthermore, the combination and adaptation of the selected novel ideas to the solution concepts leads to the patentable inventions and creation of new intellectual property.

As presented in Table 5, each case study (CS) can be served with several ideas and solution concepts: for instance, 17 ideas and 3 concepts in the CS1, 58 ideas and 8 concepts in the CS2, etc. The mean number of solution ideas proposed for each partial problem is 15,6 . The average number of ideas generated in one ideation session (IS) by a team is $9,17(\mathrm{SD}=1,51)$. The mean value of dissimilar new ideas proposed by each workshop participant in one ideation session along all case studies is $3,12(\mathrm{SD}=0,52)$. However, a missing direct comparison with a control group of engineers working without TRIZ belongs to the limitation factors of the present analysis.

Table 5. Number of ideas, solution concepts, ideation sessions and teams in the case studies.

\begin{tabular}{ccccccc}
\hline $\begin{array}{c}\text { Case } \\
\text { study }\end{array}$ & $\begin{array}{c}\text { Partial } \\
\text { problems }\end{array}$ & $\begin{array}{c}\text { Solution } \\
\text { ideas }\end{array}$ & $\begin{array}{c}\text { Solution } \\
\text { concepts }\end{array}$ & $\begin{array}{c}\text { Ideation } \\
\text { sessions } \\
\text { (IS) }\end{array}$ & $\begin{array}{c}\text { Number of } \\
\text { teams } \\
\text { (persons) }\end{array}$ & $\begin{array}{c}\text { Ideas in one } \\
\text { IS per team } \\
\text { (person) }\end{array}$ \\
\hline CS1 & 3 & 17 & 3 & 1 & $2(6)$ & $8,5(2,8)$ \\
CS2 & 3 & 58 & 8 & 2 & $3(9)$ & $9,7(3,2)$ \\
CS3 & 2 & 24 & 4 & 1 & $2(6)$ & $12,0(4,0)$ \\
CS4 & 2 & 28 & 3 & 2 & $2(6)$ & $7,0(2,3)$ \\
CS5 & 3 & 52 & 6 & 2 & $3(9)$ & $8,7(2,9)$ \\
CS6 & 3 & 55 & 4 & 2 & $3(8)$ & $9,2(3,4)$ \\
\hline Total & 15 partial & 234 & 28 con- & 10 ses- & 15 teams & Mean \\
& problems & ideas & cepts & sions & $(44$ persons) & $9,2(3,1)$ \\
\hline
\end{tabular}

\subsection{TRIZ Impact on Variety of proposed Ideas}

In order to assess the variety of the ideas proposed in the workshops, every idea was assigned to the most appropriate knowledge domain. For this purpose, both problems and generated ideas were related to the eight engineering MATCEMIB fields and their interactions [20] applied in TRIZ: Mechanical, Acoustic, Thermal, Chemical, Electric, Magnetic, Intermolecular, Biological. For example, a uniformity problem caused by the surface effects of solid particles can be assigned to the intermolecular field, and a corresponding solution idea based on ultrasound treatment - to the acoustic field.

PROBLEM FIELDS

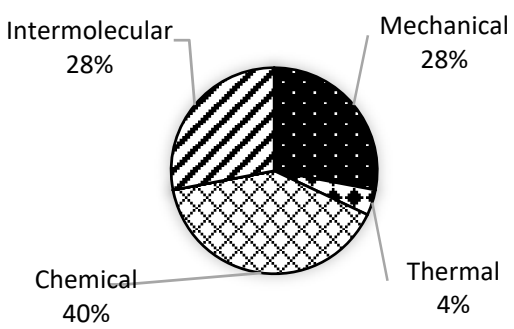

IDEAS FIELDS

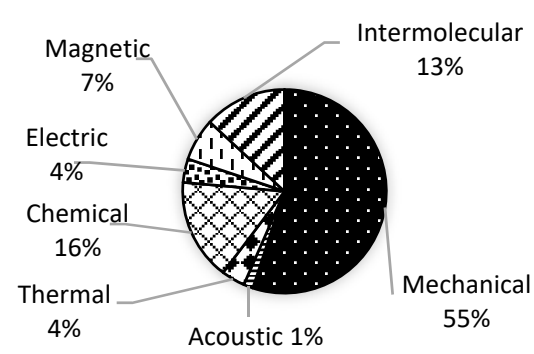

Fig. 2. Distribution of problems and ideas over the eight fields of MATCEMIB in all case studies. 
As shown in Figure 2, the 15 partial problems presented in all case studies belong to following engineering fields: chemical problems $40 \%$, mechanical problems $28 \%$, intermolecular problems $28 \%$, and thermal problems $4 \%$. At the same time, the 234 ideas from all case studies can be assigned to all fields excepting biological. As a result, the majority of the problems could be solved within mechanical (55\%), chemical (16\%) and intermolecular $(13 \%)$ knowledge domains in the process engineering.

The variety of solution ideas in relationship between the engineering domains of problems and proposed ideas is illustrated in Table 6. Thanks to the TRIZ inventive principles engineers were able to find solution ideas in 7 engineering domains for mechanical, chemical, and intermolecular problems. However, no ideas based on acoustic, electric, or magnetic fields were proposed for thermal problems.

Table 6. Relationship between engineering domains of partial problems and ideas.

\begin{tabular}{l|ccccc}
\hline $\begin{array}{r}\text { Engineering domains of } \\
\text { 15 problems }\end{array}$ & Mechanical & Thermal & Chemical & $\begin{array}{c}\text { Inter- } \\
\text { molecular }\end{array}$ \\
\hline Mechanical & $\mathrm{x}$ & $\mathrm{x}$ & $\mathrm{x}$ & $\mathrm{x}$ \\
Acoustic & $\mathrm{x}$ & & $\mathrm{x}$ & $\mathrm{x}$ \\
Thermal & $\mathrm{x}$ & $\mathrm{x}$ & $\mathrm{x}$ & $\mathrm{x}$ \\
Chemical & $\mathrm{x}$ & $\mathrm{x}$ & $\mathrm{x}$ & $\mathrm{x}$ \\
Electric & $\mathrm{x}$ & & $\mathrm{x}$ & $\mathrm{x}$ \\
Magnetic & $\mathrm{x}$ & & $\mathrm{x}$ & $\mathrm{x}$ \\
Intermolecular & $\mathrm{x}$ & $\mathrm{x}$ & $\mathrm{x}$ & $\mathrm{x}$ \\
\hline
\end{tabular}

\subsection{Quality of proposed Ideas and Ideation Efficiency}

Despite of high quantity and variety of the novel ideas proposed with TRIZ inventive principles, the industrial companies require technically feasible, economically affordable, and safe solutions. On that reason, only a smaller number of high quality ideas has been selected by the engineers for further implementation in the solution concepts taking into account the following criteria: idea value (how a partial problem is solved), implementation efforts, costs and technical risks. The number of such implementation ideas $I d$ divided by the total number of the ideas $I d_{t}$ generated in one case study (see Table 5) can characterize the efficiency of an ideation technique. These efficiency values are presented for each case study in Figure 3. For example, in the case study CS1 $\left(I d=6 ; I d_{t}=17\right)$ only $35 \%$ of all generated ideas were considered as mature for further implementation and were applied for concepts creation. The mean value of TRIZ efficiency for all Process Intensification case studies can be calculated with the formula (1) and is equal $33,8 \%$.

Thus, roughly only one third of the proposed ideas is estimated by the engineers as especially promising for process intensification. However, in the opinion of researchers many of ideas, which were not selected by engineers for implementation, possess a substantial potential for significant technological innovation in future. 


$$
E_{I d}=\frac{1}{n} \sum_{i=1}^{n} \frac{I d_{i}}{I d_{t i}}
$$

$E_{I d}-$ mean efficiency of ideation estimated on the base of all case studies

$I d_{i}$ - number of implementation ideas in one case study used for concepts creation

$I d_{t i}-$ total number of ideas generated in one case study

$n$ - number of case studies

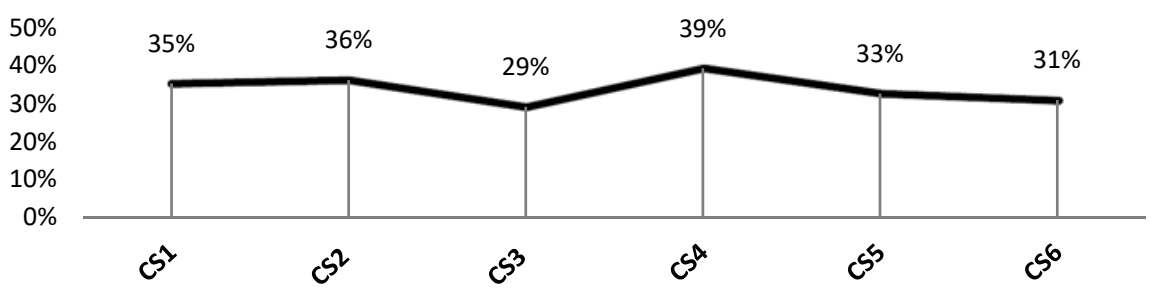

Fig. 3. Ideation efficiency with TRIZ inventive principles in the case studies CS1 - CS6, defined as the ratio of implementation ideas and total number of ideas in a case study.

\subsection{Identification of most efficient Inventive Sub-principles}

The analysis of the solution ideas and concepts created in six case studies has also resulted in identification of the most frequently used top 10 inventive sub-principles, as presented in Figure 4. These top 10 sub-principles can be generally considered as most efficient and recommended for the new development or optimization of PI equipment or methods in the field of processes involving solids handling. The identified sets of strongest sub-principles differ from the recommended group of statistically strongest inventive principles, presented in Table 3.

To the most often applied sub-principles belong Change concentration (35b), followed by Use electromagnetism (28a), and Reversed sequence (13b). It is also interesting to notice that top 10 sub-principles used in idea generation such as Periodic action (19a), Optimal performance (15a), Gaseous or liquid flows (29a), Miniaturization (17b) and Pre-arrange objects (10b) don't appear in top 10 sub-principles applied in solution concepts. Vice versa, the top 10 sub-principles Utilize harm (22a), Spheres and cylinders (14b), Different functions (3c), One step back from ideal (16a) and Rotary motion (14c) found in the solution concepts don't belong to the top 10 sub-principles in idea generation phase.

The TRIZ sub-principles mentioned above belong to the updated version of 40 inventive principles with in total 160 sub-principles presented in the previous research [17]. The study [17] analyses 155 Process Intensification technologies and 150 patent documents in the field of solid handling in the ceramic and pharmaceutical industries. It partially restructures and enhances the classical 40 inventive principles and extends them with additional 70 inventive sub-principles for the problems frequently encountered in process engineering. 


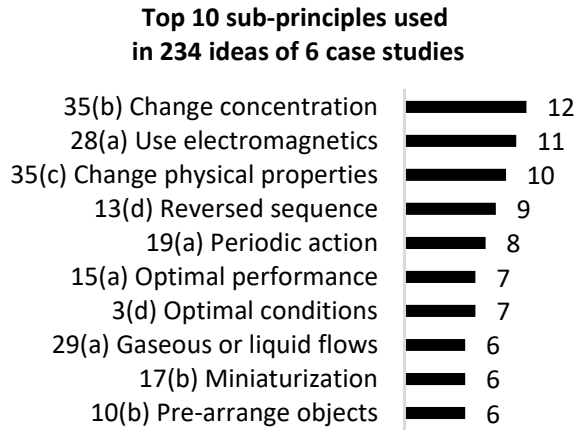

Number of mentioning
Top 10 sub-principles used in 28 concepts of 6 case studies based on 112 ideas

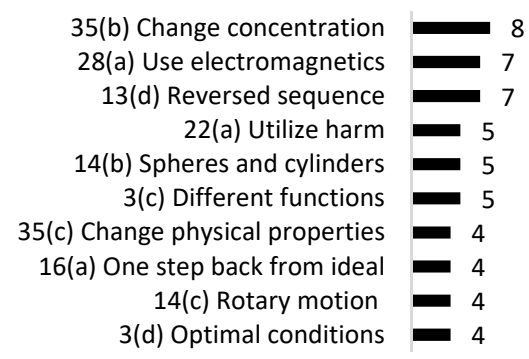

Number of mentioning

Fig. 4. Inventive sub-principles most frequently encountered in ideas and solution concepts.

The identified sets of top 10 TRIZ inventive principles and sub-principles in the analyzed case studies show clear differences to the corresponding top 10 sets of frequently used TRIZ principles and sub-principles extracted from the 155 PI technologies show some differences and from 150 patents for intensification ceramic and pharmaceutical operations with solids in previous investigation [17]. As illustrated in Figure 5, there are 9 inventive principles (No 1, 5, 6, 14, 18, 24, 28, 29 and 35) most frequently used in all three sources of analysis: I) Case studies, II) PI technologies, III) Patents.
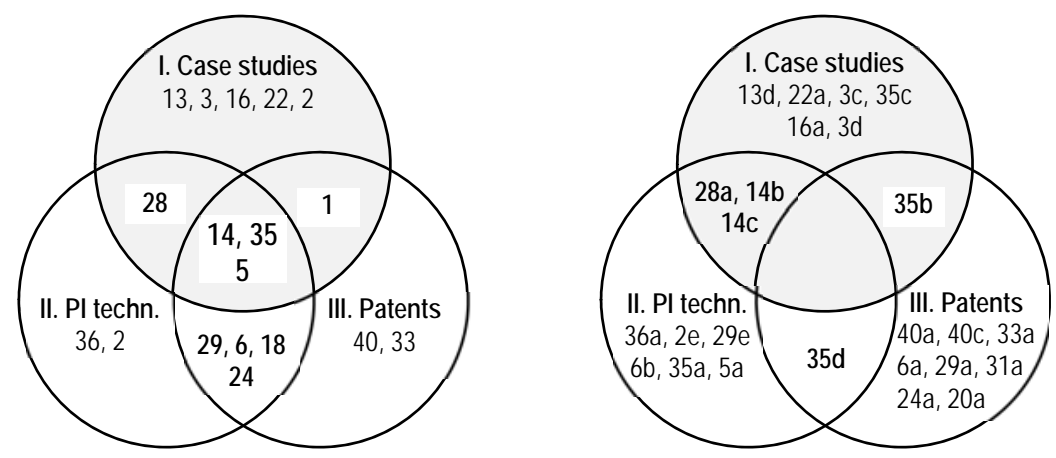

Fig. 5. Top 10 most frequently used TRIZ inventive principles (left) and sub-principles (right) in solution concepts of 6 case studies (I), 155 PI technologies (II) and 150 patent documents (III).

The comparison on the level of sub-principles delivers a higher resolution and depicts only 5 frequently used sub-principles: Spheres and cylinders (14b), Rotary motion (14c), Use electromagnetism (28a), Change concentration (35b) and Change temperature (35d). In general, the identified selection of principles and sub-principles in Fig. 5 can be recommended for problem solving in processes involving solids handling.

The top 10 inventive principles and sub-principles applied in the case studies as well as top 10 inventive principles identified in the PI technologies and patents in [17] belong to the different groups of TRIZ principles recommended for ideation in Table 3. 
This statement is illustrated in the Fig. 6. Understandably, that 9 of 10 top principles (left diagram) and sub-principles (right diagram) applied in 234 case studies (CS) ideas come from the group 1 of statistically strongest principles as group 1 was primarily recommended for ideation in each workshop. However, the solution concepts in the case studies are based on principles from all three groups. More uniform distribution of top 10 principles over the groups 1, 2 and 3 can be observed for PI technologies and patents.

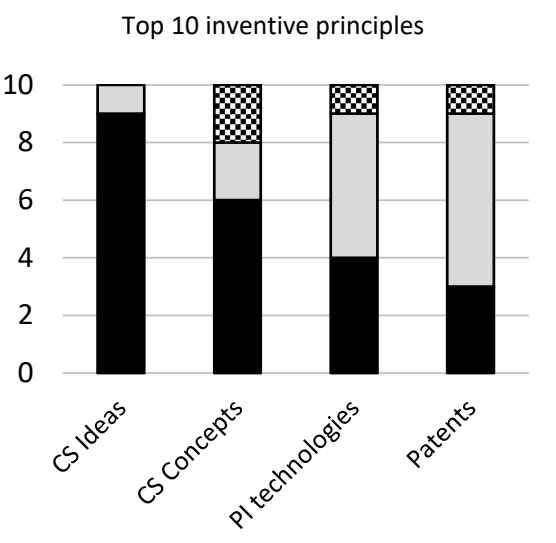

-Group 1 GGroup 2 gGroup 3
Top 10 inventive sub-principles

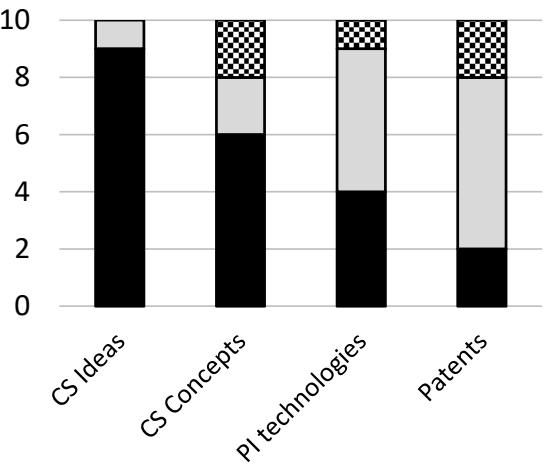

-Group 1 aroup 2 Group 3

Fig. 6. Distribution of top 10 inventive principles (left) and top 10 sub-principles (right) over 3 groups of principles recommended for ideation: Group 1: statistically strongest principles; Group 2: principles for design problems; Group 3: Principles for process engineering problems.

\subsection{Efficiency of TRIZ Application for Process Intensification}

A series of reviews has been conducted several months after the workshops to observe and assess the positive effect of TRIZ application in the case studies. The industrial teams of engineers or researchers who participated in the TRIZ workshops, evaluated the current state of their PI projects with different criteria, such costs, time expenditures, technical risks, innovation impact and TRIZ support, as presented in Table 8.

Table 8. Evaluation of the current state of PI design in case studies.

\begin{tabular}{|c|c|c|c|c|c|c|}
\hline & CS 1 & CS2 & CS3 & CS4 & CS5 & CS6 \\
\hline 1. Costs, level of investments & $40 \%$ & $60 \%$ & - & $80 \%$ & $80 \%$ & $60 \%$ \\
\hline $\begin{array}{l}\text { 2. Time expenditures for imple- } \\
\text { mentation of technology }\end{array}$ & $60 \%$ & $80 \%$ & - & $60 \%$ & - & $80 \%$ \\
\hline $\begin{array}{l}\text { 3. Level of anticipated technical } \\
\text { risks in future }\end{array}$ & $60 \%$ & $80 \%$ & - & $40 \%$ & $80 \%$ & $40 \%$ \\
\hline $\begin{array}{l}\text { 4. Innovation impact of new tech- } \\
\text { nology in terms of PI-goals }\end{array}$ & $80 \%$ & $80 \%$ & - & $100 \%$ & $100 \%$ & $100 \%$ \\
\hline 5. Supportive impact of TRIZ & $80 \%$ & $60 \%$ & - & $100 \%$ & $80 \%$ & - \\
\hline
\end{tabular}


For each criterion the following scale has been used: $100 \%$ - very high, $80 \%$ - high, $60 \%$-middle, $40 \%$ - low, $20 \%$ - very low. The estimated supportive impact of TRIZ workshops in the case studies was with on average $80 \%$ high. The evaluation results of the case study 3 could not be made available to the public.

\section{Conclusion and Outlook}

The presented research assesses the efficiency of TRIZ support for process intensification (PI) applied to solids handling in six industrial case studies in the field of chemical, pharmaceutical, ceramic, and mineral processes. The positive experience with combination of TRIZ and PI gives us confidence to extend the findings regarding TRIZ efficiency to the other fields of process engineering.

The application of TRIZ as a systematic problem-solving method demonstrates a positive impact on faster achieving PI goals. Moreover, TRIZ allows to identify and solve secondary PI problems comprehensively with numerous and interdisciplinary solution concepts. TRIZ inventive principles improve the outcomes of idea generation regarding novelty, quality, quantity, and variety of ideas.

Furthermore, it is worth to mention the identified sets and application order of the strongest inventive principles $(14,35,5,28,1,29,6,18,24,13, \ldots)$ and inventive subprinciples $(35 \mathrm{~b}, 28 \mathrm{a}, 14 \mathrm{~b}, 14 \mathrm{c}, 35 \mathrm{~d}, 13 \mathrm{~d}, 22 \mathrm{a}, 36 \mathrm{a}, 3 \mathrm{c}, 40 \mathrm{a}, \ldots$ ) which can be recommended for systematic and creative problem solving in processes involving solids handling.

The later review of the case studies progress shows that most engineers and researchers positively judge the TRIZ application in the PI practice. However, the research is still required to optimize and formalize the phase of concept creation as wells as to better identify inventive solution principles and sub-principles for other PI domains.

Acknowledgments. The authors thank the European Commission for supporting their work as part of the research project "Intensified by Design ${ }^{\circledR}$ platform for the intensification of processes involving solids handling" under H2020 SPIRE programme.

\section{References}

1. Wang, H., Mustaffar, A., Phan, A.N., Zivkovic, V., Reay, D., Law, R., Boodhoo, K.: A review of process intensification applied to solids handling. Chemical Engineering and Processing: Process Intensification, Volume 118, 78-107 (2017).

2. VDI Standard 4521: Inventive Problem Solving with TRIZ. Fundamentals and Definitions. Beuth Publishers, Berlin (2016).

3. Casner, D., Livotov, P., Masudah, Kely Da Silva, P.: TRIZ-based approach for process intensification and problem solving in process engineering: concepts and research agenda. In: Koziołek, S., Chechurin, L., Collan, M. (eds): Advances and Impacts of the Theory of Inventive Problem Solving. The TRIZ Methodology, Tools and Case Studies. Springer (2018).

4. Hua, Z., Yang, J., Coulibaly, S., Zhang, B.: Integration TRIZ with problem-solving tools: a literature review from 1995 to 2006. International Journal of Business Innovation and Research, 111-128 (2010). 
5. Ilevbare, I.M., Probert, D., Phaal, R.: A review of TRIZ, and its benefits and challenges in practice. Technovation 33, 2:30-37 (2013)

6. Chechurin, L., Borgianni, Y.: Understanding TRIZ through the review of top cited publications. Computers in Industry, Volume 82, 119-134 (2016).

7. Casner, D., Livotov, P.: Advanced innovation design approach for process engineering. Proceedings of the 21st Int. Conf. on Engineering Design (ICED 17), Vol 4: Design Methods and Tools, pp. 653-662. Vancouver (2017).

8. Pokhrel, C., Cruz, C., Ramirez, Y., Kraslawski, A.: Adaptation of TRIZ contradiction matrix for solving problems in process engineering. Chemical Engineering Research and Design, Volume 103, 3-10 (2015).

9. Livotov P, Petrov V (2013) TRIZ Innovation Technology. Product Development and Inventive Problem Solving. Handbook. 284 pages, Innovator (06) 01/2013, ISSN 1866-4180.

10. Kim, J., Kim, J., Lee, Y., Lim, W., Moon, I.: Application of TRIZ creativity intensification approach to chemical process safety. Journal of Loss Prevention in the Process Industries, Volume 22, 6:1039-1043 (2009).

11. Abdul Rahim, Z., Lim Sing Sheng, I., Nooh, A.B.: TRIZ methodology for applied chemical engineering: A case study of new product development. Chemical Engineering Research and Design, Volume 103, 11-24 (2015).

12. Abramov, O., Kogan, S., Mitnik-Gankin, L., Sigalovsky, I., Smirnov, A.: TRIZ-based approach for accelerating innovation in chemical engineering. Chemical Engineering Research and Design, Volume 103, 25-31 (2015).

13. Srinivasan, R., Kraslawski, A.: Application of the TRIZ creativity enhancement approach to design of inherently safer chemical processes. Chemical Engineering and Processing: Process Intensification, Volume 45, 6:507-514 (2006).

14. Cortes Robles, G., Negny, S., Le Lann, J.M.: Case-based reasoning and TRIZ: A coupling for innovative conception in Chemical Engineering. Chemical Engineering and Processing: Process Intensification, Volume 48, 239-249 (2009).

15. Livotov, P.: Advanced Innovation Design Approach: towards Integration of TRIZ Methodology into Innovation Design Process. Journal of the European TRIZ Association INNOVATOR, 02-2017 (04), ISSN: 1866-4180, p. 1-3 (2017).

16. Shah, J. J., Vargas-Hernandez, N., \& Smith, S. M. (2003). Metrics for measuring ideation effectiveness. Design Studies, 24(2), 111-134. DOI: 10.1016/S0142-694X(02)00034-0

17. Livotov, P., Chandra Sekaran, A.P., Law, R., Mas'udah, Reay, D.: Systematic Innovation in Process Engineering: Linking TRIZ and Process Intensification. In: Chechurin, L., Collan, M. (eds): Advances in Systematic Creativity. Springer Nature, 978-3-319-78074-0 (2018).

18. Grierson, B., Fraser, I., Morrison, A., Chisholm, G., 2003. 40 Principles - Chemical Illustrations. The Triz Journal. https://triz-journal.com/40-principles-chemical-illustrations/, last accessed 2018/03/29 (2003).

19. Hipple, J.: 40 inventive principles with examples for chemical engineering. TRIZ Journal Homepage, www.triz-journal.com/archives/2005/06/06.pdf, last accessed 2018/03/29. (2005).

20. Belski, I., Livotov P., Mayer, O., Eight Fields of MATCEMIB Help Students to Generate More Ideas. Proc. CIRP, Vol. 39, 2016, Pages 85-90. DOI 10.1016/j.procir.2016.01.170 (2016). 